\title{
RESEARCH
}

Open Access

\section{Recent changes in trends of opioid overdose deaths in North America}

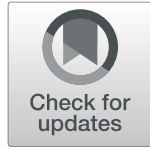

\author{
Sameer Imtiaz ${ }^{{ }^{*}}$ (D), Kevin D. Shield ${ }^{1,2}$, Benedikt Fischer ${ }^{3,4,5,6}$, Tara Elton-Marshall ${ }^{1,2,7,8}$, Bundit Sornpaisarn,
} Charlotte Probst ${ }^{1}$ and Jürgen Rehm ${ }^{1,2,3,4,9,10,11}$

\begin{abstract}
Background: As several regulatory and environmental changes have occurred in North America, trends in overdose deaths were examined in the United States (US), Ontario and British Columbia (BC), including changes in consumption levels of prescription opioids (PO) and overdose deaths, changes in correlations between consumption levels of PO and overdose deaths and modeled differences between observed and predicted overdose deaths if no changes had occurred.
\end{abstract}

Methods: Consumption levels of PO included defined daily doses for statistical purposes per million inhabitants per day for the US and Canada (2001-2015). Overdose deaths included opioid overdose deaths for the US (2001-2017) and Ontario (2003-2017) and illicit drug overdose deaths for BC (2001-2017). The analytic techniques included structural break point analyses, Pearson product-moment correlations and multivariate Gaussian state space modeling.

Results: Consumption levels of PO changed in the US in 2010 and in Canada in 2012. Overdose deaths changed in the US in 2014 and in Ontario and BC in 2015. Prior to the observed changes in consumption levels of PO, there were positive correlations between consumption levels of PO and overdose deaths in the US $(r=0.99, p<0.001)$ and Ontario ( $r=0.92, p=0.003)$. After the observed changes in consumption levels of $\mathrm{PO}$, there was a negative correlation between consumption levels of PO and overdose deaths in the US ( $r=-0.99, p=0.002)$. Observed overdose deaths exceeded predicted overdose deaths by 5.7 (95\% Confidence Interval [Cl]: 4.8-6.6), 3.5 (95\% Cl: 3.2-3.8) and 21.8 (95\% Cl: 18.6-24.9) deaths per 100,000 people in the US, Ontario and BC, respectively in 2017. These excess deaths corresponded to $37.7 \%$ (95\% Cl: 31.9-43.6), 39.2\% (95\% Cl: 36.3-42.1) and $72.2 \%$ (95\% Cl: 61.882.6) of observed overdose deaths in the US, Ontario and BC, respectively in 2017.

Conclusions: The opioid crisis has evolved in North America, as a sizeable proportion of overdose deaths are now attributable to the several regulatory and environmental changes. These findings necessitate substance use policies to be conceptualized more broadly as well as the continued expansion of harm reduction services and types of pharmacotherapy interventions.

Keywords: Analgesics, opioid, Prescription drug, Death, Drug overdose, United States, Canada, Ontario, British Columbia

\footnotetext{
*Correspondence: sameer.imtiaz@gmail.com; sameer.imtiaz@camh.ca

${ }^{1}$ Institute for Mental Health Policy Research, Centre for Addiction and Mental

Health, 33 Russell Street, Toronto, ON M5S 2S1, Canada

Full list of author information is available at the end of the article
}

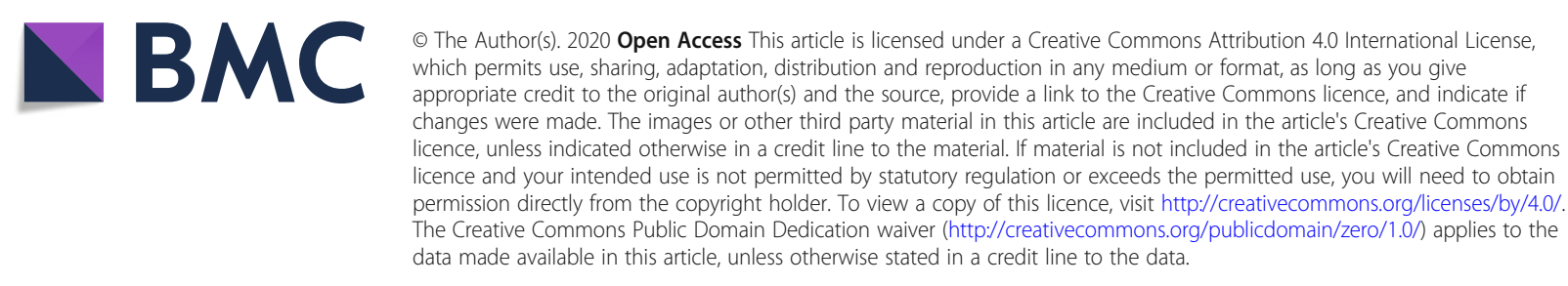




\section{Introduction}

Opioid overdose deaths represent a significant public health crisis in North America. Parallel to the rise in prescription opioid use and non-medical prescription opioid use, overdose deaths in North America have reached unprecedented levels over the past two decades [1-3]. These deaths increased steadily in the United States $[4,5]$ and the Canadian province of Ontario $[6,7]$. They remained stable in the Canadian province of British Columbia from 2004 to 2013, with substantial increases from then onwards [8]. Opioid overdoses were responsible for 49,068 deaths in the United States in 2017 , constituting the majority of illicit drug overdose deaths $(67.8 \%)$, far exceeding motor vehicle injury deaths (37,133 deaths), previously the largest cause of unintentional injury deaths [9]. Although comprehensive national data are not available, opioid overdoses resulted in more than 4000 deaths in Canada in 2017 [2]. Overdose deaths are now one of the main causes of the recent decrease in life expectancies in the United States [10-12]. A plateauing of life expectancy has been documented in Canada. However, opioid overdose deaths are partly responsible for decreases in life expectancies observed in British Columbia from 2014 to 2016 [13].

One of the primary drivers of opioid overdose deaths has been opioid prescribing. At the population level, it has been demonstrated based on data from the past decade that there are strong temporal correlations between opioid prescribing - overall and formulation-specific and opioid-related harms, including opioid overdose deaths [14-16]. Recent evidence suggests that although opioid overdose deaths have been increasing in the United States, opioid prescribing has declined [17]. Indeed, the diversion and misuse of prescription opioids plateaued or declined in the United States between 2011 and 2013 [5]. Similar declines in opioid prescribing are also evident in Canada [18]. These declines may be attributable to the recent introduction of co-occurring regulatory changes, including, but not limited to, the implementation of prescription-monitoring programs $[19,20]$ and crackdowns on inappropriate prescription dispensation (e.g. pill mills) [21], as well as restrictions on opioid marketing [22] and opioid prescribing [23-25] (including the development of prescription guidelines) [26, 27].

In addition to the abovementioned regulatory changes, other environmental changes may have more recently impacted opioid overdose deaths as well, including decreases in the availability of prescription opioids and cost of illicit opioids. Although fentanyl is a prescription drug [28], illicit fentanyl and fentanyl analogs are also commonly available [29, 30]; however, toxicological analyses of opioid overdose deaths are often not able to distinguish between prescription fentanyl and illicit fentanyl
$[29,31]$. It is suggested that the main driver of opioid overdose deaths more recently in the United States and Canada is illicit opioids, including illicit fentanyl $[1,3$, 32,33 ] and heroin [34], unlike the period prior to the regulatory changes $[35,36]$. At the same time, health authorities have implemented and scaled up a variety of harm reduction interventions in the United States and Canada, including supervised consumption facilities, distribution of naloxone kits and expansion of addiction pharmacotherapy [37].

However, the overall impact of these regulatory and environmental changes on opioid overdose deaths is not well characterized. As such, we analyzed recent data from the United States, Ontario and British Columbia to examine trends in opioid overdose deaths to inform the public health response. Our specific objectives were as follows,

1. Examine changes in consumption levels of prescription opioids and overdose deaths.

2. Assess changes in the correlations between consumption levels of prescription opioids and overdose deaths.

3. Compare predicted overdose deaths with observed overdose deaths if no regulatory or environmental changes had occurred.

\section{Methods}

\section{Data sources}

National data on consumption levels of prescription opioids in the United States and Canada (2001 to 2015) were obtained in the form of defined daily doses for statistical purposes per million inhabitants per day (S-DDD) from the International Narcotics Control Board (see [28] for the last iteration of the report). This metric facilitates comparisons between different kinds of opioids (including codeine, fentanyl, hydrocodone, hydromorphone, methadone, morphine, oxycodone, pethidine, tilidine, others) based on their potency, which is computed by divisions of the annual consumption of prescription opioids by 365, population (millions) during the year and defined daily dose. Importantly, this metric captures the total availability or volume of prescription opioids in the population. As this metric is reported according to three-year moving average intervals, annual estimates were ascertained using the midpoint of a three-year moving average (e.g., moving average for 2014 to 2016 was used for 2015).

Consistent with the definition of the Centers for Disease Control and Prevention [38], opioid overdose deaths in the United States (2001 to 2017) included drug overdose deaths (International Classification of Diseases, Tenth Revision (ICD-10) X40-44, X60-64, X85 and Y10-14) that involved opioids (ICD-10 T40.0-40.4 and T40.6) as a 
contributory cause [38], which were obtained from the United States National Vital Statistics System Multiple Cause-of-Death Files [39]. Contrastingly, national time series on opioid overdose deaths are not available in Canada. In addition, case definitions of opioid overdose deaths often differ between provinces. Therefore, Ontario and British Columbia were examined, two provinces representing about half of the Canadian population, who experienced the largest number of opioid overdose deaths in 2017 [2]. Based on the definition of the Office of the Chief Coroner for Ontario [40], opioid overdose deaths in Ontario (2003 to 2017) included all deaths where opioid overdose was considered to be a contributor to the cause of death (including intentional deaths). On the other hand, unintentional illicit drug overdose deaths served as an approximation of opioid overdose deaths in British Columbia (2001 to 2017) [41]. Based on the definition of the British Columbia Coroners Service, illicit drug overdose deaths included accidental and undetermined deaths that involved illicit drugs and unprescribed medications, as well as their combinations with other prescribed medications [41]. We note that while the vast majority of illicit drug overdose deaths involved opioids, non-opioid overdose deaths (e.g., cocaine and methamphetamine) were included as well.

All data on consumption levels of prescription opioids and overdose deaths are presented in Table S1 in the Supplementary Appendix.

\section{Statistical analyses}

To test for changes over time in consumption levels of prescription opioids and overdose deaths, supremum Wald tests were conducted, which search for the maximum of the sample individual Wald tests constructed by testing each possible break date in the sample [42, 43]. A symmetric data trimming of $15 \%$ was performed to avoid testing for break points that were too close to the beginning or end of the time series [42]. The trends in consumption levels of prescription opioids and overdose deaths were characterized separately for the periods before and after the break points of each jurisdiction.

Correlations between the consumption levels of prescription opioids and overdose deaths were quantified using Pearson's product-moment correlations. For each computed correlation, 95\% Confidence Intervals (CIs) and $P$ values were also generated. These correlations were calculated separately for the periods before and after changes in consumption levels of prescription opioids in each jurisdiction, as determined by the abovementioned break point analyses.

Overdose deaths assuming no significant regulatory or environmental changes were modeled to determine the extent the observed deaths differed from predicted deaths based on prior trends. Predicted overdose deaths were modelled using multivariate Gaussian state space models [44]. No restrictions were assumed for the covariance structures of the level or noise components. Initial estimates were calculated according to the covariance matrix of the observed series in keeping with the procedures outlined by Helske [45]. These initial values were used in subsequent estimation procedures, which determined final model parameters through importance sampling (using 1000 samples) and a BroydenFletcher-Goldfarb-Shanno algorithm for likelihood computation. The smoothed estimates of states were generated using Kalman filtering and smoothing, with exact diffuse initialization using a univariate approach for exponential family state space models. Recursive residuals from the models were inspected to check whether autocorrelation remained in the residuals.

All analyses were performed using the statistical software $R$ version 3.5 .1 and the statistical software package KFAS for R $[45,46]$.

\section{Ethics compliance}

Research ethics committee review and approval were not required, as aggregate data were extracted from publicly available sources.

\section{Results}

Trends in consumption levels of prescription opioids and overdose deaths

Consumption levels of prescription opioids increased by 130.3\% in the United States from 2001 to 2011 (22,524 to 51,873 S-DDD) (Fig. 1). The consumption levels of prescription opioids in the United States changed in 2012, decreasing by $10.3 \%$ from 2012 to 2015 (51,374 to $46,090 \mathrm{~S}$ DDD). Similar changes occurred in Canada in 2010. Consumption levels of prescription opioids increased by $202.8 \%$ from 2001 to 2009 (8713 to 26,380 S-DDD) and increased by $6.4 \%$ from 2010 to 2015 (28,731 to 30,570 S-DDD).

Overdose deaths changed in the United States in 2014 (Table 1). After increasing by $138.2 \%$ from 2001 to 2013, overdose deaths increased by $67.7 \%$ from 2014 to 2017 . Similar changes occurred in both Ontario and British Columbia in 2015. Overdose deaths in Ontario increased by $65.3 \%$ from 2003 to 2014 and by $68.8 \%$ from 2015 to 2017. On the other hand, overdose deaths in British Columbia increased by $36.8 \%$ from 2001 to 2014 and by 169.0\% from 2015 to 2017.

\section{Correlations between consumption levels of prescription opioids and overdose deaths}

Prior to the observed changes in consumption levels of prescription opioids, consumption levels of prescription opioids and overdose deaths were positively correlated in the United States (R: 0.989; 95\% CI: 0.957 to 0.997) and Ontario (R: 0.922; 95\% CI: 0.553 to 0.988) (Table 2). After the observed changes in consumption levels of 


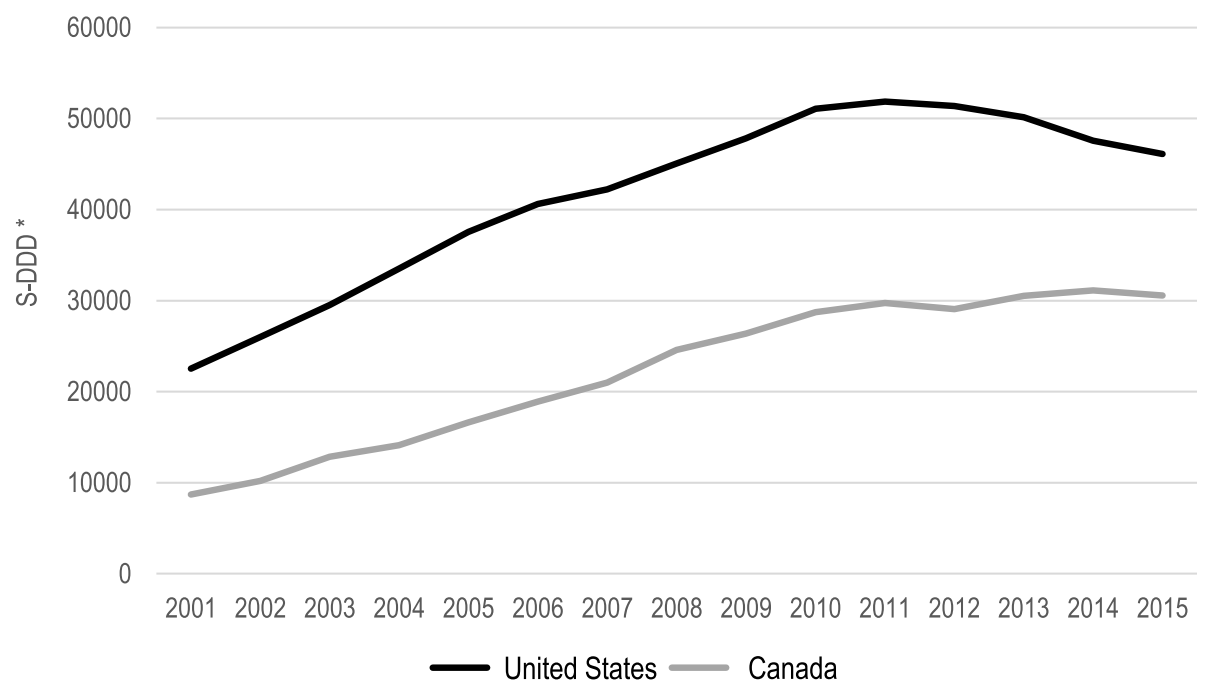

*S-DDD: Defined Daily Doses for Statistical Purposed Per Million Inhabitants Per Day

Fig. 1 Defined daily doses for statistical purposes per million inhabitants per day of prescription opioids

prescription opioids, consumption levels of prescription opioids and overdose deaths were negatively correlated in the United States (R: $-0.985,95 \%$ CI: -1.00 to 0.442), not Ontario. Such correlations were not observed during either period in British Columbia.

\section{Predicted overdose deaths compared to observed overdose deaths}

Based on the period before the changes in overdose deaths, overdose deaths were predicted for all three jurisdictions (Fig. 2). If overdose deaths had continued to increase at rates observed before the changes, 9.4 (95\% CI: 8.5 to 10.2), 5.1 (95\% CI: 4.9 to 5.3 ) and 8.4
(95\% CI: 5.2 to 11.5) overdose deaths per 100,000 people were predicted for the United States, Ontario and British Columbia in 2017, respectively. The observed overdose deaths exceeded the predicted overdose deaths by 5.7 (95\% CI: 4.8 to 6.6), 3.5 (95\% CI: 3.2 to 3.8 ) and 21.8 ( $95 \%$ CI: 18.6 to 24.9 ) deaths per 100,000 people in the United States, Ontario and British Columbia in 2017, respectively. The differences corresponded to $37.7 \%$ (95\% CI: 31.9 to $43.6 \%$ ), $39.2 \%$ (95\% CI: 36.3 to $42.1 \%$ ) and $72.2 \%$ (95\% CI: 61.8 to 82.6\%) of observed overdose deaths in the United States, Ontario and British Columbia in 2017, respectively.

Table 1 Changes in overdose deaths

\begin{tabular}{|c|c|c|c|c|c|}
\hline \multirow{2}{*}{$\begin{array}{l}\text { Country } \\
\text { and } \\
\text { province }\end{array}$} & \multirow{2}{*}{$\begin{array}{l}\text { Time } \\
\text { period }\end{array}$} & \multicolumn{4}{|l|}{ Overdose deaths $^{\mathbf{a}}$} \\
\hline & & $\begin{array}{l}\text { From } \\
\text { (Per 100,000 people) }\end{array}$ & $\begin{array}{l}\text { To } \\
\text { (Per 100,000 people) }\end{array}$ & $\begin{array}{l}\text { Percentage change } \\
(\%)\end{array}$ & $\begin{array}{l}\text { Annualized Change } \\
\text { (Per } 100,000 \text { people per year) }\end{array}$ \\
\hline \multicolumn{6}{|l|}{ Canada } \\
\hline \multicolumn{6}{|c|}{ Ontario } \\
\hline & 2003-2014 & 3.0 & 4.9 & $65.3 \%$ & 0.2 \\
\hline & 2015-2017 & 5.3 & 8.9 & $68.8 \%$ & 1.3 \\
\hline \multicolumn{6}{|c|}{ British Columbia } \\
\hline & 2001-2014 & 5.8 & 7.9 & $36.8 \%$ & 0.2 \\
\hline & 2015-2017 & 11.2 & 30.1 & $169.0 \%$ & 7.4 \\
\hline \multicolumn{6}{|c|}{ United States } \\
\hline & 2001-2013 & 3.3 & 7.9 & $138.2 \%$ & 0.4 \\
\hline & 2014-2017 & 9.0 & 15.1 & $67.7 \%$ & 1.8 \\
\hline
\end{tabular}

${ }^{a}$ As determined by the break point analyses, overdose deaths changed in Ontario in 2015, in British Columbia in 2015 and in the United States in 2014 
Table 2 Correlations between defined daily doses for statistical purposes per million inhabitants per day of prescription opioids and overdose deaths

\begin{tabular}{|c|c|c|c|c|c|c|c|}
\hline \multirow[t]{2}{*}{$\begin{array}{l}\text { Country and } \\
\text { province }\end{array}$} & \multirow[t]{2}{*}{$\begin{array}{l}\text { Data } \\
\text { availability }\end{array}$} & \multicolumn{3}{|c|}{$\begin{array}{l}\text { Pearson correlation coefficient: } \\
\text { pre-change in S-DDD of prescription }_{\text {opioids }^{\mathbf{a}}}\end{array}$} & \multicolumn{3}{|c|}{$\begin{array}{l}\text { Pearson correlation coefficient: } \\
\text { post change in S-DDD of prescription } \\
\text { opioids }^{\mathbf{b}}\end{array}$} \\
\hline & & Estimate & (95\% Cls) & $\boldsymbol{P}$ value & Estimate & (95\% Cls) & $\boldsymbol{P}$ value \\
\hline \multicolumn{8}{|l|}{ Canada } \\
\hline Ontarioc,d & 2003-2015 & 0.922 & $(0.553,0.988)$ & 0.003 & 0.760 & $(-0.135,0.972)$ & 0.080 \\
\hline British Columbia ${ }^{c, e}$ & $2001-2015$ & -0.288 & $(-0.799,0.465)$ & 0.452 & 0.730 & $(-0.200,0.968)$ & 0.100 \\
\hline United States $^{d}$ & $2001-2015$ & 0.989 & $(0.957,0.997)$ & $<0.001$ & -0.985 & $(-1.00,-0.442)$ & 0.002 \\
\hline
\end{tabular}

apre-change in consumption levels of prescription opioids was 2001 to 2011 in the United States, 2003 to 2009 in Ontario and 2001 to 2009 in British Columbia, as determined by the break point analyses

${ }^{b}$ Post change in consumption levels of prescription opioids was 2012 to 2015 in United States, 2010 to 2015 in Ontario and 2010 to 2015 in British Columbia, as determined by the break point analyses

'Defined daily doses data for statistical purposes per million inhabitants per day are not province-specific

${ }^{\mathrm{d} O v e r d o s e}$ deaths are due to opioid use

e Overdose deaths are due to illicit drug use

\section{Discussion}

Consumption levels of prescription opioids have decreased in the United States since 2012 and increased slightly in Canada since 2010. In agreement with findings from our present analyses, others have also demonstrated reductions in morphine milligram equivalents per capita since 2010 and opioid prescription rates per capita since 2012 in the United States [17]. The slight variation in findings is attributable to selection of outcome metrics and analytical strategies. Similar decreases are also evident in Canada since 2012, although comprehensive time series are not available [18, 47].

Overdose deaths have increased in the United States since 2014 and in Ontario and British Columbia since 2015. Prior to changes in the consumption levels of prescription opioids in the United States and Ontario, consumption levels of prescription opioids were positively correlated with overdose deaths. However, consumption levels of prescription opioids were negatively correlated with overdose deaths in the United States after 2012; as consumption levels of prescription opioids decreased, overdose deaths increased. Consumption levels of prescription opioids are no longer associated with overdose deaths in Ontario, while they were not associated with overdose deaths during the pre-change or post-change periods in British Columbia.

Overdose deaths have increased at a greater rate than would be expected in the absence of regulatory and environmental changes in the United States since 2014 and in Ontario and British Columbia since 2015. Our modeling predictions are corroborated by another examination of opioid-related deaths in Ontario from 2013 to 2016, where $39.8 \%$ of deaths were documented to have occurred among those without an active opioid prescription [4]. Almost identical findings were obtained from our present analyses, as $39.2 \%$ of overdose deaths were attributable to regulatory and environmental changes in Ontario in 2017.

Decreases in consumption levels of prescription opioids reflect changes in opioid prescribing practices. The reductions in morphine milligram equivalents per capita in the United States highlighted above stem from

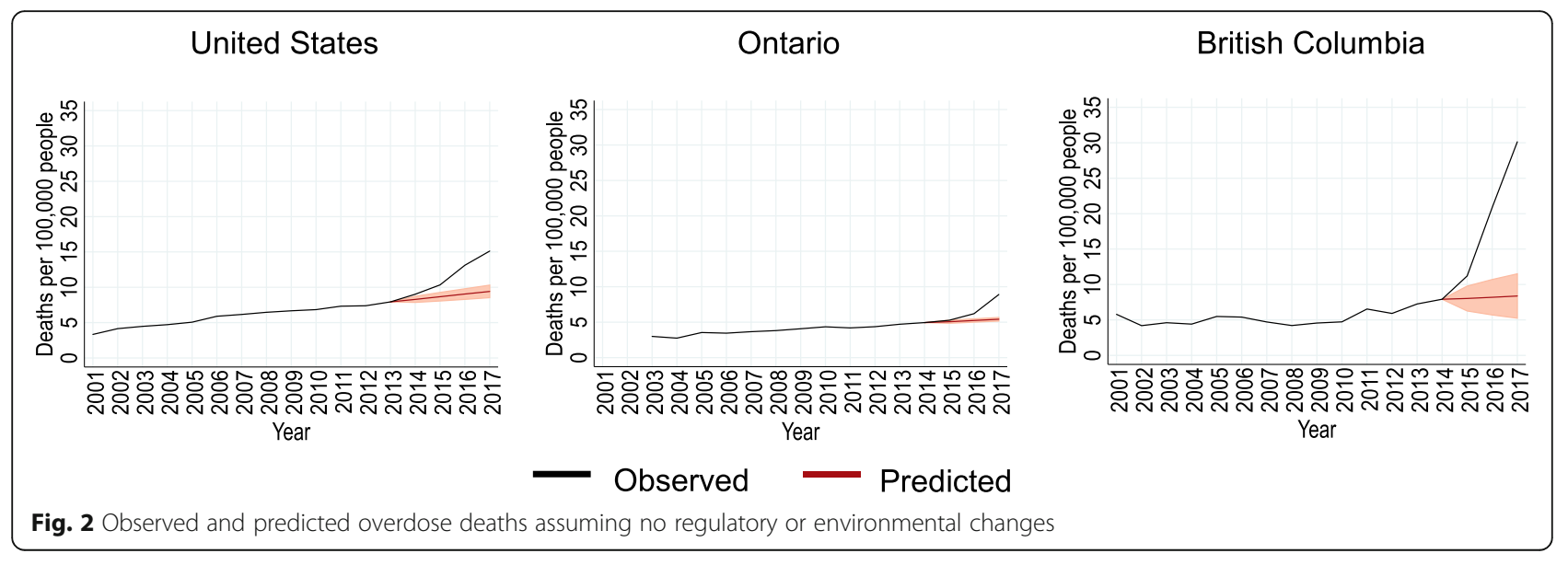


reductions in opioid prescriptions and doses per opioid prescription [17]. However, as the duration of opioid prescriptions has increased at the same time in the United States, it is probable that opioid therapy initiation is occurring less often, but those receiving opioids are likely to continue receiving them [17]. Although comprehensive time series are not available for all of Canada, similar trends have been noted based on recent observations from select provinces, which indicate reductions in opioid prescriptions (overall and initiations), as well as reductions in long-term opioid prescriptions and doses per opioid prescription for long-term prescriptions [47].

Changes in the correlations between consumption levels of prescription opioids and overdose deaths in the United States and Ontario likely stem from the recent regulatory and environmental changes. Illicit opioids have often replaced prescription opioids as the substance of choice (see for the transition from prescription opioids to heroin in general: [48-50]; for illicit fentanyl: [51]). Importantly, other illegal substances often include added fentanyl because of its availability and cheap price [52]. Consistent with transitions in the types of opioids, state adoption of prescription-monitoring programs intended to curtail inappropriate opioid prescribing has been shown to be associated with steadily increasing heroin overdose deaths in the United States [53]. The null correlations observed for British Columbia may be explained by a different outcome metric in illicit drug overdose deaths, as well as a different drug environment that features greater availability of illicit opioids, given the geographical proximity to countries where such substance originate [31].

The comparison of predicted and observed overdose deaths underscores jurisdictional differences in the impacts of regulatory and environmental changes. About $40 \%$ of overdose deaths in the United States and Ontario were attributable to these recent changes in 2017. The situation was drastically different in British Columbia, where more than $70 \%$ of overdose deaths were attributable to these recent changes in 2017. More recent observations indicate that the differences between the jurisdictions may be narrowing as well. Indeed, opioid overdose deaths involving synthetic opioids (including fentanyl) increased in the United States from 46 to $60 \%$ between 2016 and 2017 [54]. On that same note, unintentional opioid overdose deaths involving fentanyl increased from 45 to $69 \%$ in Ontario and from 69 to $83 \%$ in British Columbia between 2016 and 2017 [2].

Although overdose deaths are typically classified statistically as being due to one substance in toxicological analyses, they are often caused by the adverse and interactive effects of multiple substances [55]. These interactions may involve different opioids (e.g., prescription opioids combined with other illegal opioids) with additive effects, or combinations with sedatives (e.g., benzodiazepines and alcohol), all of which have been identified as major contributors to overdose deaths $[6$, 49, 56, 57]. An analysis of 13 states in the United States demonstrated that alcohol was involved in $18.5 \%$ of prescription opioid-related emergency visits and $22.1 \%$ of prescription opioid-related deaths [58]. On a similar note, about $75 \%$ of opioid overdose deaths involve nonopioid substances in Canada [2]. Basing prevention interventions solely on the basis of such toxicological analyses is therefore somewhat misleading.

Substance use policies should be conceptualized with a broad focus [59, 60]. Reductions in opioid prescribing are needed [25], as consumption has risen sharply during the past two decades in North America [61] beyond the support of solid evidence for efficacy [62], resulting in extensive harms. However, despite the apparent need to address this problem, the potential solutions are not clear [63]. It is evident that the regulatory and environmental changes have resulted in more harms, as the supply voids created by the depletion of prescription opioids have been filled by the proliferation of illicit opioids, rendering the current crisis as one involving toxic drug exposure [63, 64]. The situation necessitates protection of the public through the provision of a safe opioid supply (see [63-65] for proposed models). Additional measures are also needed, such as expanding access to different types of opioid use disorder pharmacotherapy (e.g. morphine, hydromorphone) [66], as well as scalingup harm reduction interventions to prevent overdose deaths, including the distribution of Naloxone and implementation of supervised injection facilities (for overviews, see [67-69]).

\section{Study limitations}

There are some limitations that should be considered in the interpretation of the findings. First, the classification of overdose deaths differed between the three examined jurisdictions. The main difference pertained to the inclusion of intentional injury, with intentional overdoses included in the United States and Ontario, unlike British Columbia. In addition, there were differences between the United States and Ontario and British Columbia in terms of the inclusion of overdose deaths involving illicit drugs other than opioids. Regardless of the definitions used, unintentional overdose deaths are often hard to differentiate from intentional overdose deaths, thereby creating additional measurement error [70]. On that same note, there may have been other subjective and procedural differences in the ascertainment of overdose deaths by health authorities between the three jurisdictions. Second, there may have been ascertainment differences in overdose deaths within the three jurisdictions, as the likelihood of case detection may have differed during the study 
period. Third, metrics that combine the use of different opioids into a single indicator rely on assumptions concerning the patterns and potency. The S-DDD operationalized in the present analyses is no exception. This metric attempts to adjust for different potencies by considering the recommended daily use of each prescription opioid, which may lead to bias (e.g., [71]). Although some bias may be included because prescription practices may differ according to world regions, it is clear that the S-DDD is best available metric for inter-jurisdictional comparisons over time. Fourth, impacts of the specific regulatory and environmental changes could not be characterized separately, given the limited points of observation $(N=15$ for Ontario and $N=17$ for British Columbia and United States) in between co-occurring changes. On that same note, the correlations between consumption levels of prescription opioids and overdose deaths after the observed changes in consumption levels of prescription opioids were based on four observations for the United States and six observations for Ontario and British Columbia.

\section{Conclusion}

As the regulatory and environmental changes have occurred in North America, there have been changes in the correlations between consumption levels of prescription opioids and overdose deaths in the United States and Ontario. In all three examined jurisdictions, a sizeable proportion of overdose deaths can be attributed to these changes.

\section{Supplementary information}

Supplementary information accompanies this paper at https://doi.org/10. 1186/s13011-020-00308-z.

Additional file 1: Data on consumption levels of prescription opioids and overdose deaths.

\section{Abbreviations \\ Cl: Confidence Interval; ICD-10: International Classification of Diseases, Tenth Revision; S-DDD: Defined daily doses for statistical purposes per million inhabitants per day \\ Acknowledgements \\ Not applicable}

\begin{abstract}
Authors' contributions
Sameer Imtiaz and Jürgen Rehm conceived the idea for the study. Sameer Imtiaz, Benedikt Fischer, Kevin Shield and Jürgen Rehm outlined the design Sameer Imtiaz and Kevin D. Shield managed the data acquisition and conducted the data analyses. Jürgen Rehm drafted the manuscript. All authors critically revised the manuscript for intellectual content. All authors read and approved the final manuscript.
\end{abstract}

\section{Funding}

Sameer Imtiaz, Bundit Sornpaisarn, Tara Elton-Marhsall, Jürgen Rehm acknowledge funding from the Canadian Institutes of Health Research's Institute of Neurosciences, Mental Health and Addiction (Canadian Research Initiative on Substance Misuse Ontario Node Grant SMN-13950). Benedikt Fischer acknowledges research grant and contract funding from the Canadian Institutes of Health Research and Canadian Government Agencies (e.g., Health
Canada), with all funding support limited to public entity sources only, as well as research funding support from the Hugh Green Foundation Chair in Addiction Research and related research support, held at the University of Auckland, Auckland, New Zealand. The funding sources had no role in study design, collection, analysis and interpretation of data, preparation of the manuscript or decision to submit the manuscript for publication.

Availability of data and materials

All data generated or analyzed during this study are included in this published article and its supplementary appendix.

Ethics approval and consent to participate

Not applicable.

\section{Consent for publication}

Not applicable.

\section{Competing interests}

Jürgen Rehm has received grants and personal fees from Lundbeck, unrelated to the present research. All other authors declare declare that they have no competing interests.

\section{Author details}

${ }^{1}$ Institute for Mental Health Policy Research, Centre for Addiction and Mental Health, 33 Russell Street, Toronto, ON M5S 2S1, Canada. ${ }^{2}$ Dalla Lana School of Public Health, University of Toronto, 6th Floor, 155 College Street, Toronto, ON M5T 3M7, Canada. Institute of Medical Science, University of Toronto, Room 2374, 1 King's College Circle, Toronto, ON M5S 1A8, Canada. ${ }^{4}$ Department of Psychiatry, University of Toronto, 8th Floor, 250 College Street, Toronto, ON M5T 1R8, Canada. ${ }^{5}$ Schools of Population Health and Pharmacy, Faculty of Medical and Health Sciences, University of Auckland, 85 Park Road, Grafton, Auckland 1023, New Zealand. ${ }^{6}$ Centre for Applied Research in Mental Health \& Addiction, Faculty of Health Sciences, Simon Fraser University, 515 W. Hastings Street, Vancouver V6B 5K3, Canada. ${ }^{7}$ Ontario Tobacco Research Unit, Centre for Addiction and Mental Health, 33 Russell Street, Toronto, ON M5S 2S1, Canada. ${ }^{8}$ Department of Epidemiology and Biostatistics, Schulich School of Medicine and Dentistry, Western University, Kresge Building, 1151 Richmond Street, London, ON N6A 5C1, Canada. ${ }^{9}$ Campbell Family Mental Health Research Institute, Centre for Addiction and Mental Health, 250 College Street, Toronto, ON M5T 1R8, Canada. ${ }^{10}$ Institute for Clinical Psychology and Psychotherapy, TU Dresden, Chemnitzer Str. 46, 01187, Dresden, Germany. " Department of International Health Projects, Institute for Leadership and Health Management, I.M. Sechenov First Moscow State Medical University, Trubetskaya Str., 8, B. 2, Moscow 119992, Russian Federation.

Received: 11 April 2020 Accepted: 19 August 2020

Published online: 31 August 2020

\section{References}

1. National Institute on Drug Abuse. Overdose death rates - revised august 2018. Washington, District of Columbia: National Institute on Drug Abuse; 2018. Available from: https://www.drugabuse.gov/related-topics/trendsstatistics/overdose-death-rates.

2. Special Advisory Committee on the Epidemic of Opioid Overdoses. National report: Apparent opioid-related deaths in Canada (January 2016 to December 2018) Web-based report. Ottawa, Ontario: Public Health Agency of Canada; 2019. Available from: https://www.canada.ca/en/health-canada/ services/substance-use/problematic-prescription-drug-use/opioids/apparentopioid-related-deaths.html.

3. Centers for Disease Control and Prevention. 2018 Annual surveillance report of drug-related risks and outcomes: United States. Atlanta, Georgia: Centers for Disease Control and Prevention; 2018.

4. Gomes T, Khuu W, Martins D, Tadrous M, Mamdani MM, Paterson JM, et al. Contributions of prescribed and non-prescribed opioids to opioid related deaths: population based cohort study in Ontario, Canada. BMJ. 2018;362: k3207.

5. Dart RC, Severtson SG, Bucher-Bartelson B. Trends in opioid analgesic abuse and mortality in the United States. N Engl J Med. 2015;372(16):1573-4.

6. Gomes T, Martins D, Singh S, Mamdani M, Dhalla I, Paterson M, et al. Opioid related deaths in Ontario between 1991 and 2010: a report by the Ontario 
drug policy research network. Ontario Drug Policy Research Network: Toronto, Ontario; 2014

7. Fischer B, Jones W, Urbanoski K, Skinner R, Rehm J. Correlations between prescription opioid analgesic dispensing levels and related mortality and morbidity in Ontario, Canada, 2005-2011. Drug Alcohol Rev. 2014;33(1):19-26.

8. Gladstone EJ, Smolina K, Morgan SG. Trends and sex differences in prescription opioid deaths in British Columbia, Canada. Inj Prev. 2016;22(4): 288-90.

9. National Center for Statistics and Analysis. 2017 Fatal Motor Vehicle Crashes: Overview. (Traffic Safety Facts Research Note. Report No. DOT HS 812 603). Washington, District of Columbia: National Highway Traffic Safety Administration; 2018

10. Rehm J, Probst C. Decreases of life expectancy despite decreases in noncommunicable disease mortality: the role of substance use and socioeconomic status. Eur Addict Res. 2018:24(2):53-9.

11. Case A, Deaton A. Rising morbidity and mortality in midlife among white non-Hispanic Americans in the 21st century. Proc Natl Acad Sci U S A. 2015; 112(49):15078-83.

12. Case A, Deaton A. Mortality and morbidity in the 21 (st) century. Brookings Pap Econ Act. 2017;2017:397-476.

13. Ye X, Sutherland J, Henry B, Tyndall M, Kendall PRW. At-a-glance - impact of drug overdose-related deaths on life expectancy at birth in British Columbia. Health Promot Chronic Dis Prev Can. 2018;38(6):248-51.

14. Imtiaz S, Shield KD, Fischer B, Rehm J. Harms of prescription opioid use in the United States. Subst Abuse Treat Prev Policy. 2014;9(1):43.

15. Fischer B, Jones W, Rehm J. High correlations between levels of consumption and mortality related to strong prescription opioid analgesics in British Columbia and Ontario, 2005-2009. Pharmacoepidemiol Drug Saf. 2013;22(4):438-42.

16. Bohnert AS, Valenstein M, Bair MJ, Ganoczy D, McCarthy JF, llgen MA, et al. Association between opioid prescribing patterns and opioid overdoserelated deaths. JAMA. 2011:305(13):1315-21.

17. Guy GP Jr, Zhang K, Bohm MK, Losby J, Lewis B, Young R, et al. Vital signs: changes in opioid prescribing in the United States, 2006-2015. MMWR Morb Mortal Wkly Rep. 2017;66(26):697-704.

18. Canadian Institute for Health Information. Pan-Canadian trends in the prescribing of opioids, 2012 to 2016. Ottawa: Canadian Institute for Health Information; 2017.

19. Reifler LM, Droz D, Bailey JE, Schnoll SH, Fant R, Dart RC, et al. Do prescription monitoring programs impact state trends in opioid abuse/ misuse? Pain Med. 2012;13(3):434-42.

20. Gomes T, Juurlink D, Yao Z, Camacho X, Paterson JM, Singh S, et al. Impact of legislation and a prescription monitoring program on the prevalence of potentially inappropriate prescriptions for monitored drugs in Ontario: a time series analysis. CMAJ Open. 2014;2(4):E256-61.

21. Rutkow L, Chang HY, Daubresse M, Webster DW, Stuart EA, Alexander GC. Effect of Florida's prescription drug monitoring program and pill mill Laws on opioid prescribing and use. JAMA Intern Med. 2015;175(10):1642-9.

22. Psaty BM, Merrill JO. Addressing the opioid epidemic - opportunities in the Postmarketing setting. N Engl J Med. 2017;376(16):1502-4.

23. Covvey JR. Recent developments toward the safer use of opioids, with a focus on hydrocodone. Res Social Adm Pharm. 2015;11(6):901-8.

24. Kanouse AB, Compton P. The epidemic of prescription opioid abuse, the subsequent rising prevalence of heroin use, and the federal response. J Pain Palliat Care Pharmacother. 2015;29(2):102-14.

25. Fischer B, Rehm J, Tyndall M. Effective Canadian policy to reduce harms from prescription opioids: learning from past failures. CMAJ. 2016;188(1718):1240-4.

26. Dowell D, Haegerich TM, Chou R. CDC guideline for prescribing opioids for chronic pain - United States, 2016. MMWR Recomm Rep. 2016;65:1-49.

27. Meara E, Horwitz JR, Powell W, McClelland L, Zhou W, O'Malley AJ, et al. State legal restrictions and prescription-opioid use among disabled adults. N Engl J Med. 2016;375(1):44-53.

28. International Narcotics Control Board. Narcotic drugs 2017: estimated world requirements for 2018 - statistics for 2016. New York, New York: International Narcotics Control Board; 2018.

29. World Health Organization. Essential medicines and health products: fortyfirst meeting of the expert committee on drug dependence (Geneva, Switzerland, 12-16 November 2018). Geneva, Switzerland: World Health Organization; 2018. Available from: https://www.who.int/medicines/access/ controlled-substances/ecdd_41_meeting/en/.
30. Ruzycki S, Yarema M. Fentanyl misuse. CMAJ. 2016;188(9):673

31. Fischer B, Vojtila L, Rehm J. The 'fentanyl epidemic' in Canada - some cautionary observations focusing on opioid-related mortality. Prev Med. 2018;107:109-13.

32. Canadian Centre on Substance Abuse. Deaths involving Fentanyl in Canada, 2009-2014. Ottawa, Ontario: Canadian Centre on Substance Abuse: 2015.

33. Howlett K, Giovannetti J, Vanderklippe N, Perreaux L. A killer high: How Canada got addicted to fentanyl. The Globe and Mail; 2017 [Issue date: 04/ $11 / 2017]$

34. Centers for Disease Control and Prevention. Today's heroin epidemic. Atlanta, Georgia: Centers for Disease Control and Prevention; 2015. Available from: https://www.cdc.gov/vitalsigns/heroin/index.html.

35. Paulozzi LJ. Prescription drug overdoses: a review. J Saf Res. 2012;43:283-9.

36. Paulozzi LJ, Ryan GW. Opioid analgesics and rates of fatal drug poisoning in the United States. Am J Prev Med. 2006;31(6):506-11.

37. Irvine MA, Kuo M, Buxton JA, Balshaw R, Otterstatter M, Macdougall $L$, et al. Modelling the combined impact of interventions in averting deaths during a synthetic-opioid overdose epidemic. Addiction. 2019;114(9):1602-13.

38. Rudd RA, Seth P, David F, Scholl L. Increases in drug and opioid-involved overdose deaths - United States, 2010-2015. MMWR Morb Mortal Wkly Rep. 2016;65(50-51):1445-52.

39. Centers for Disease Control and Prevention. Multiple Cause of Death 19992017. Atlanta: Centers for Disease Control and Prevention; 2017. Available from: https://wonder.cdc.gov/wonder/help/mcd.html.

40. Ontario Agency for Health Protection and Promotion (Public Health Ontario). Interactive Opioid Tool Toronto, Ontario; 2018 [Available from: https://www.publichealthontario.ca/en/dataandanalytics/pages/opioid.aspx].

41. British Columbia Coroners Service. Illicit drug overdose deaths in BC (January 1, 2009 - march 31, 2019). Victoria, British Columbia: British Columbia Coroners Service; 2019. Available from: https://www2.gov.bc.ca/ assets/gov/birth-adoption-death-marriage-and-divorce/deaths/coronersservice/statistical/illicit-drug.pdf.

42. Andrews DWK. Tests for parameter instability and structural change with unknown change point. Econometrica. 1993;61(4):821-56.

43. Quandt RE. Tests of the hypothesis that a linear regression system obeys two separate regimes. J Am Stat Assoc. 1960;55:324-30.

44. Durbin J, Koopman SJ. Time series analysis by state space methods. 2nd ed. Oxford: Oxford University Press; 2012.

45. Helske J. KFAS: exponential family state space models in R. J Stat Softw. 2017:78(10):1-39.

46. R Core Team. A language and environment for statistical computing. $R$ Foundation for statistical computing. Vienna, Austria: R Foundation for statistical computing; 2018

47. Canadian Institute for Health Information. Opioid prescribing in Canada: how are practices changing? Ottawa, Ontario: Canadian Institute for Health Information; 2019.

48. Cicero TJ, Ellis MS, Surratt HL, Kurtz SP. The changing face of heroin use in the United States: a retrospective analysis of the past 50 years. JAMA Psychiatry. 2014;71(7):821-6.

49. Jones $C M$. Heroin use and heroin use risk behaviors among nonmedical users of prescription opioid pain relievers - United States, 2002-2004 and 2008-2010. Drug Alcohol Depend. 2013;132(1-2):95-100.

50. Muhuri PK, Gfroerer JC, Davies MC. Associations of nonmedical pain reliever use and initiation of heroin use in the United States. Rockville, Maryland: Center for Behavioral Health Statistics and Quality; 2013.

51. National Academies of Sciences, Engineering, and Medicine. Pain Management and the Opioid Epidemic: Balancing Societal and Individual Benefits and Risks of Prescription Opioid Use. Washington, District of Columbia: The National Academies Press; 2017.

52. Frank RG, Pollack HA. Addressing the fentanyl threat to public health. $N$ Engl J Med. 2017;376(7):605-7.

53. Martins SS, Ponicki W, Smith N, Rivera-Aguirre A, Davis CS, Fink DS, et al. Prescription drug monitoring programs operational characteristics and fatal heroin poisoning. Int J Drug Policy. 2019;74:174-80.

54. Scholl L, Seth P, Kariisa M, Wilson N, Baldwin G. Drug and opioid-involved overdose deaths — United States, 2013-2017. MMWR Morb Mortal Wkly Rep. 2019;67:1419-27.

55. Warner M, Trinidad JP, Bastian BA, Miniño AM, Hedegaard H. Drugs most frequently involved in drug overdose deaths: United States, 2010-2014. National Vital Statistics Reports. Hyattsville, Maryland: National Center for Health Statistics; 2016. Report No.: 65(10). 
56. Jones JD, Mogali S, Comer SD. Polydrug abuse: a review of opioid and benzodiazepine combination use. Drug Alcohol Depend. 2012;125(1-2):8-18

57. Modarai F, Mack K, Hicks P, Benoit S, Park S, Jones C, et al. Relationship of opioid prescription sales and overdoses, North Carolina. Drug Alcohol Depend. 2013;132(1-2):81-6.

58. Jones CM, Paulozzi $\sqcup$, Mack KA. Alcohol involvement in opioid pain reliever and benzodiazepine drug abuse-related emergency department visits and drug-related deaths - United States, 2010. MMWR Morb Mortal Wkly Rep. 2014;63:881-5.

59. Anderson P, Braddick F, Conrod P, Gual A, Hellman M, Matrai S, et al. The new governance of addictive substances and behaviours. Oxford, United Kingdom: Oxford University Press; 2017.

60. Rehm J, Anderson P, Fischer B, Gual A, Room R. Policy implications of marked reversals of population life expectancy caused by substance use. BMC Med. 2016:14:42.

61. U.S. Department of Health and Human Services Office of the Surgeon General. Facing Addiction in America: The Surgeon General's Report on Alcohol, Drugs, and Health. Washington, District of Columbia: U.S. Department of Health and Human Services; 2016.

62. Busse JW, Wang L, Kamaleldin M, Craigie S, Riva JJ, Montoya L, et al. Opioids for chronic noncancer pain: a systematic review and meta-analysis. JAMA. 2018:320(23):2448-60.

63. Tyndall M. An emergency response to the opioid overdose crisis in Canada: a regulated opioid distribution program. CMAJ. 2018;190(2):E35-E6.

64. Fischer B, Pang M, Tyndall M. The opioid death crisis in Canada: crucial lessons for public health. Lancet Public Health. 2019;4(2):e81-e2.

65. Thomson E, Wilson D, Mullins G, Livingston A, Shaver L, McBain L. Heroin compassion clubs: a co-operative model to reduce opioid overdose deaths and disrupt organized Crime's role in fentanyl, money laundering and housing unaffordability. British Columbia Centre on Substance Use: Vancouver, British Columbia; 2019.

66. Volkow ND, Frieden TR, Hyde PS, Cha SS. Medication-assisted therapies-tackling the opioid-overdose epidemic. N Engl J Med. 2014;370(22):2063-6.

67. Csete J, Kamarulzaman A, Kazatchkine M, Altice F, Balicki M, Buxton J, et al. Public health and international drug policy: report of the Johns Hopkins lancet commission on drug policy and health. Lancet. 2016;387(10026): $1427-80$.

68. Volkow N. America's addiction to opioids: heroin and prescription drug abuse. Presentation at the (US) Senate Caucus on International Narcotics Control; 2014

69. Beletsky L, Rich JD, Walley AY. Prevention of fatal opioid overdose. JAMA. 2012;308(18):1863-4.

70. Bohnert AS, McCarthy JF, Ignacio RV, Ilgen MA, Eisenberg A, Blow FC. Misclassification of suicide deaths: examining the psychiatric history of overdose decedents. Inj Prev. 2013;19(5):326-30.

71. Nielsen S, Gisev N, Bruno R, Hall W, Cohen M, Larance B, et al. Defined daily doses (DDD) do not accurately reflect opioid doses used in contemporary chronic pain treatment. Pharmacoepidemiol Drug Saf. 2017;26(5):587-91.

\section{Publisher's Note}

Springer Nature remains neutral with regard to jurisdictional claims in published maps and institutional affiliations.

Ready to submit your research? Choose BMC and benefit from:

- fast, convenient online submission

- thorough peer review by experienced researchers in your field

- rapid publication on acceptance

- support for research data, including large and complex data types

- gold Open Access which fosters wider collaboration and increased citations

- maximum visibility for your research: over $100 \mathrm{M}$ website views per year

At $\mathrm{BMC}$, research is always in progress.

Learn more biomedcentral.com/submissions 